\title{
Pharmacogenetics of cytochrome P450 2B6 (CYP2B6): advances on polymorphisms, mechanisms, and clinical relevance
}

\author{
Ulrich M. Zanger ${ }^{1,2 *}$ and Kathrin Klein ${ }^{1,2}$ \\ ${ }^{1}$ Dr. Margarete Fischer-Bosch Institute of Clinical Pharmacology, Stuttgart, Germany \\ ${ }^{2}$ The University of Tuebingen, Tuebingen, Germany
}

Edited by:

José A. Agúndez, University of Extremadura, Spain

Reviewed by:

Chin Eap, University of Lausanne Medical School, Switzerland

Rajeev K. Mehlotra, Case Western

Reserve University, USA

${ }^{*}$ Correspondence:

Ulrich M. Zanger, Dr. Margarete

Fischer Bosch Institute of Clinical

Pharmacology, Auerbachstrasse 112,

70376 Stuttgart, Germany.

e-mail: uli.zanger@ikp-stuttgart.de
Cytochrome P450 2B6 (CYP2B6) belongs to the minor drug metabolizing P450s in human liver. Expression is highly variable both between individuals and within individuals, owing to non-genetic factors, genetic polymorphisms, inducibility, and irreversible inhibition by many compounds. Drugs metabolized mainly by CYP2B6 include artemisinin, bupropion, cyclophosphamide, efavirenz, ketamine, and methadone. CYP2B6 is one of the most polymorphic CYP genes in humans and variants have been shown to affect transcriptional regulation, splicing, mRNA and protein expression, and catalytic activity. Some variants appear to affect several functional levels simultaneously, thus, combined in haplotypes, leading to complex interactions between substrate-dependent and -independent mechanisms. The most common functionally deficient allele is CYP2B6*6 [Q172H, K262R], which occurs at frequencies of 15 to over $60 \%$ in different populations. The allele leads to lower expression in liver due to erroneous splicing. Recent investigations suggest that the amino acid changes contribute complex substrate-dependent effects at the activity level, although data from recombinant systems used by different researchers are not well in agreement with each other. Another important variant, CYP2B6*18 [I328T], occurs predominantly in Africans (4-12\%) and does not express functional protein. A large number of uncharacterized variants are currently emerging from different ethnicities in the course of the 1000 Genomes Project. The CYP2B6 polymorphism is clinically relevant for HIV-infected patients treated with the reverse transcriptase inhibitor efavirenz, but it is increasingly being recognized for other drug substrates. This review summarizes recent advances on the functional and clinical significance of CYP2B6 and its genetic polymorphism, with particular emphasis on the comparison of kinetic data obtained with different substrates for variants expressed in different recombinant expression systems.

Keywords: bupropion, cyclophosphamide, cytochrome P450, drug metabolism, drug-drug interaction, efavirenz, pharmacogenetics, pharmacogenomics

\section{INTRODUCTION}

The cytochrome P450 (CYP) enzyme CYP2B6 is one of about a dozen human CYPs that are primarily involved in the biotransformation of drugs and other xenobiotics. The CYP2B6 gene and its closely related pseudogene, CYP2B7, are located in a tandem head-to-tail arrangement within a large CYP2 gene cluster on the long arm of chromosome 19 (Hoffman et al., 2001; Figure 1). The orthologous genes in dog, mouse, and rat are termed CYP2B11, Cyp2b10, and CYP2B1, respectively, but in contrast to other mammalian species, CYP2B6 is the only functional isozyme of its subfamily in humans (Nelson et al., 2004). Owing to the existence of extensive genetic polymorphism as well as strong inhibitors and inducers, its activity is highly variable in the population. For some clinically used drugs including the antiretroviral agents efavirenz and nevirapine, CYP2B6 single nucleotide polymorphisms have been shown to be useful predictors of pharmacokinetics and drug response (reviewed in Zanger et al., 2007; Telenti and Zanger, 2008; Rakhmanina and van den Anker, 2010). However, recent data indicate that pharmacogenetic mechanisms are complex, appear on several levels of gene expression from the initial mRNA transcript to splice variants (pre-mRNA splicing and mRNA expression) to altered proteins, and affect function in various ways including substrate-dependent and substrate-independent effects. Several previous reviews are available that cover the biochemical pharmacology, molecular genetics, and pharmacogenetics of this enzyme at various degrees of detail (Ekins and Wrighton, 1999; Turpeinen et al., 2006; Hodgson and Rose, 2007; Zanger et al., 2007; Wang and Tompkins, 2008; Mo et al., 2009; Turpeinen and Zanger, 2012). The purpose of this review is to summarize recent advances in areas that have an impact on variable expression of CYP2B6 and the mechanisms and impact of CYP2B6 polymorphism, as observed by various in vitro approaches as well as in in vivo studies, and to discuss their functional and clinical implications.

\section{VARIABILITY OF EXPRESSION AND TRANSCRIPTIONAL REGULATION}

Cytochrome P450 2B6 is primarily expressed in the liver where its contribution to the total microsomal P450 pool has been estimated 


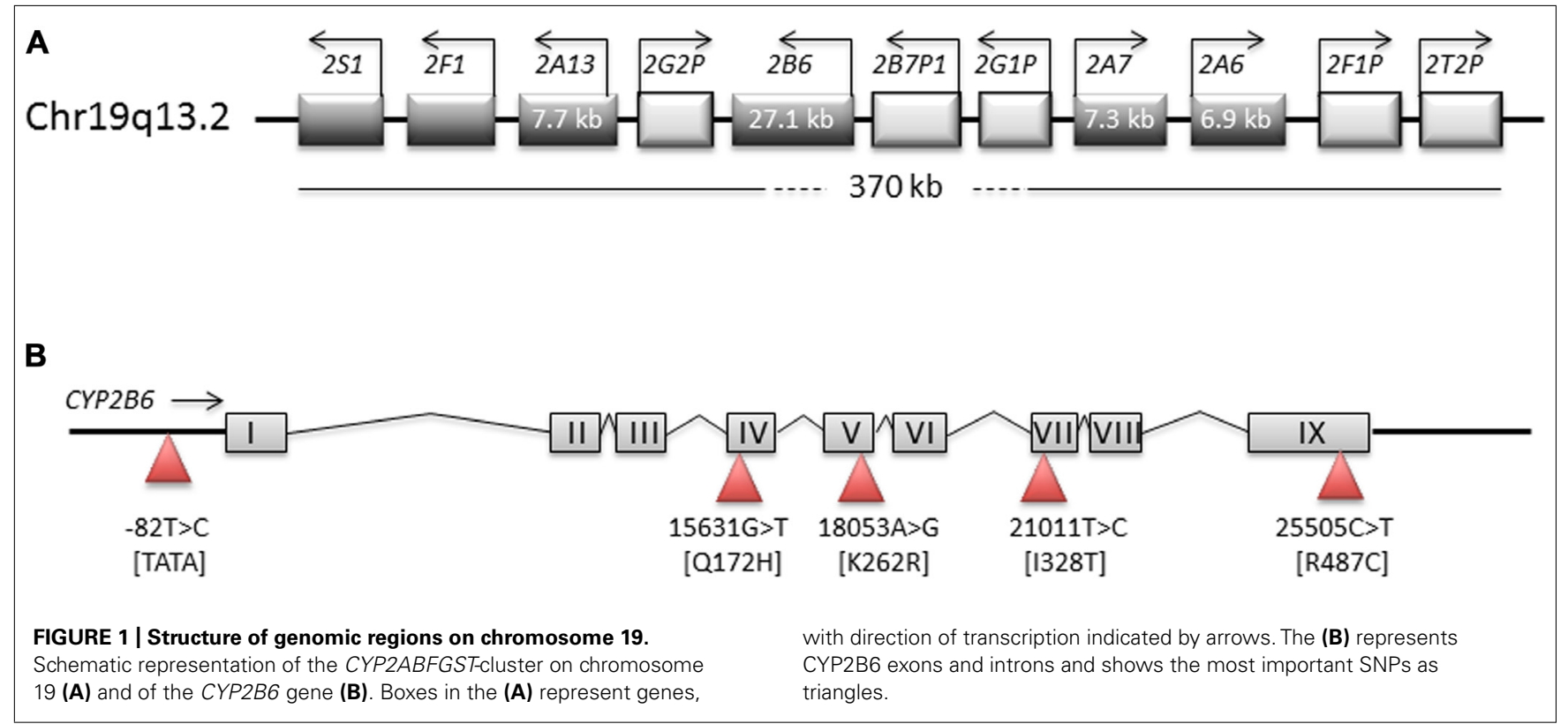

to be within a range of about $1-10 \%$, with a large inter-individual variability at protein level of roughly 100-fold (see Zanger et al., 2007 for review and references therein). Although some earlier studies reported expression in only a fraction of human livers, newer studies with better antibodies found CYP2B6 to be present in all investigated human adult liver samples (Hofmann et al., 2008) while up to one-third of pediatric samples contained no detectable protein (Croom et al., 2009). In the latter study, ontogenic differences were studied in liver microsomes from 217 pediatric liver donors. Hepatic median CYP2B6 protein levels were about twofold higher in the period between birth and 30 days postnatal compared to fetal samples, and protein levels varied already over 25-fold in both of these age groups (Croom et al., 2009). Maturation effects may further depend on genotype, as suggested in a study on HIV-infected children treated with efavirenz (Sueyoshi et al., 1999; Wang et al., 2003; Faucette et al., 2004, 2007).

One of the most important factors contributing to intra- as well as inter-individual variability is enzyme induction, i.e., de novo protein synthesis following exposure to certain chemicals. Regulation of $C Y P 2 B$ gene expression represents the archetypal example of enzyme induction (Remmer et al., 1973). Human CYP2B6 is strongly inducible by several drugs including "classical" inducers such as rifampicin, phenytoin, and phenobarbital involving a so-called phenobarbital-responsive enhancer module (PBREM) at $-1.7 \mathrm{~kb}$ of the CYP2B6 gene promoter, and a distal xenobiotics-responsive enhancer module (XREM, -8.5 kb), to which pregnane $\mathrm{X}$ receptor (PXR, NR1I2) and/or constitutive androstane receptor (CAR, NR1I3) bind to mediate increased transcription (Sueyoshi et al., 1999; Wang et al., 2003; Faucette et al., 2004, 2007). Since other CYPs are regulated by overlapping sets of nuclear receptors, CYP2B6 is often co-induced with CYP2C enzymes and CYP3A4. CYP2B6 inducers identified to date include cyclophosphamide (Gervot et al., 1999), hyperforin (Goodwin et al., 2001), artemisinin antimalarials (Simonsson et al., 2003; Burk et al., 2005), carbamazepine (Oscarson et al., 2006; Desta et al., 2007), metamizole (Saussele et al., 2007; Qin et al., 2012), ritonavir (Kharasch et al., 2008), the insect repellent N,N-diethyl$m$-toluamide (DEET; Das et al., 2008), statins (Feidt et al., 2010), efavirenz (Ngaimisi et al., 2010; Habtewold et al., 2011). Interestingly, in the latter study, gender influenced the inducibility of efavirenz 8-hydroxylation, which was higher in women than in the men (Ngaimisi et al., 2010). In addition to therapeutic drugs, pesticides were found to be powerful inducers of CYP2B6 and other CYPs through interaction with both PXR and CAR (Das et al., 2008). Induction of CYP2B6 and other cytochromes P450 and its clinical consequences has been reviewed by others (Pelkonen et al., 2008; Mo et al., 2009).

Sex differences in liver expression have been observed in a number of studies. Females liver donors had higher amounts of CYP2B6 mRNA (3.9-fold), protein (1.7-fold), and enzyme activity (1.6-fold) compared to male subjects in a study of 80 ethnically mixed samples (Lamba et al., 2003). In a study with 235 Caucasian liver donors, female samples had 1.6-fold higher expression level of CYP2B6 mRNA, however, this difference did not translate into higher protein and activity levels and no sex difference was found when only liver donors without presurgical drug exposure were considered (Hofmann et al., 2008). Discrepant effects of sex on pharmacokinetics of CYP2B6 substrates, which may be due to other confounders such as age or smoking status, were also found in vivo. Higher bupropion hydroxylation rates were found in adolescent females compared to males (Stewart et al., 2001) but not in adults (Hsyu et al., 1997). For efavirenz, several studies reported elevated plasma concentrations in female compared to male patients, which is in contrast to the abovementioned in vitro findings and may be explained by other factors such as differences in body fat content and distribution (Burger et al., 2006; Nyakutira et al., 2008; Mukonzo et al., 2009). The influence of age on CYP2B6 expression may also depend on sex, as only males showed a significant increase of liver CYP2B6 at higher age (Yang et al., 2010). 
Besides liver, CYP2B6 is also consistently expressed in different parts of respiratory and gastrointestinal tracts, including lung and nasal mucosa, and also in skin and the kidneys (Choudhary et al., 2003; Dutheil et al., 2008; Thelen and Dressman, 2009; Leclerc et al., 2010). The significance of CYP2B6 in these extrahepatic tissues is currently unknown, but it should be remembered that the enzyme is probably the most important one for many environmental toxins such as pesticides, and its presence in tissues with barrier function may thus contribute substantially to protection against these chemicals. In addition, the presence of CYP2B6 in brain has been demonstrated in human and primate brain tissue samples and smoking, alcohol consumption, and genetic polymorphism have been suggested to contribute to its variability in this organ (Miksys et al., 2003). In general, CYP levels in extrahepatic tissues are far below those of liver, but the localization to specific regions in the brain may contribute to the activation or inactivation of centrally acting drugs and to neurological side effects of certain medications or abused drugs, e.g., "ecstasy" [1methyl-4-phenyl-1,2,3,6-tetrahydropyridine (MPTP), see below]. This may also explain why efficacy for some centrally acting drugs is not well correlated to their plasma levels. The potential role of brain-expressed CYPs including CYP2B6 in the biotransformation of centrally acting drugs has been reviewed by others (Meyer et al., 2007; Ferguson and Tyndale, 2011).

\section{THE CHEMICAL INTERACTION PROFILE OF CYP2B6}

Recent studies have revealed crystal structures of the CYP2B6 wild-type and K262R variant in complex with various inhibitors at providing first views into its active site and its plasticity to adopt different conformations when binding different ligands (Gay etal., 2010; Shah etal., 2011; Wilderman and Halpert, 2012). Substrates of CYP2B6 are usually fairly lipophilic, neutral or weakly basic non-planar molecules with one or two hydrogen bond acceptors (Lewis et al., 1999, 2004). The CYP2B6 substrate selectivity comprises many diverse chemicals, including not only clinically used drugs but also many environmental chemicals such as pesticides (Turpeinen et al., 2006; Hodgson and Rose, 2007; Turpeinen and Zanger, 2012). Therapeutically important drugs metabolized primarily by CYP2B6 include the prodrug cyclophosphamide, which is converted to the direct precursor of the cytotoxic metabolites, phosphoramide mustard and acrolein, by 4-hydroxylation (Huang et al., 2000; Roy et al., 2005), the non-nucleoside reverse transcriptase inhibitor (NNRTI), efavirenz, which is 8-hydroxylated to become pharmacologically inactive (Ward et al., 2003; Desta et al., 2007), the atypical antidepressant and smoking cessation agent bupropion, which is converted to pharmacologically active hydroxybupropion (Faucette et al., 2000; Hesse et al., 2000; Turpeinen et al., 2005b), the anesthetics propofol (Court et al., 2001; Oda et al., 2001) and ketamine (Desta et al., 2012), the analgesic pethidine (meperidine; Ramírez et al., 2004); the $\mu$-opioid receptor agonist, methadone (Totah et al., 2008), the antimalarial artemisinin (Svensson and Ashton, 1999; Asimus and Ashton, 2009), among numerous additional metabolic pathways of other drugs, to which CYP2B6 contributes in part, such as the antiretroviral, nevirapine (Erickson et al., 1999), and many others (Turpeinen and Zanger, 2012). Metabolic pathways suitable as probe for CYP2B6 activity include S-mephenytoin $N$-demethylation (Ko et al., 1998), bupropion hydroxylation (Faucette et al., 2000; Fuhr et al., 2007) and efavirenz, based on in vitro investigations (Ward et al., 2003; Desta et al., 2007).

Endogenous substances metabolized by the enzyme include arachidonic acid, lauric acid, 17beta-estradiol, estrone, ethinylestradiol, and testosterone 16 $\alpha$ - and 16 $\beta$-hydroxylation (Ekins et al., 1998).

Cytochrome P450 2B6 furthermore participates in the biotransformation of the abused drug "ecstasy" ( $N$-methyl3,4-methylenedioxymethamphetamine, MDMA), which is $N$ demethylated leading to potentially neurotoxic metabolites (Kreth et al., 2000). It also plays a minor role in nicotine metabolism (Yamazaki et al., 1999; Yamanaka et al., 2005). CYP2B6 has furthermore been found to be of importance in the metabolism of pesticides and other environmental chemicals and pollutants (Hodgson and Rose, 2007). In particular the bioactivating oxidation of the organophosphorus insecticides chlorpyrifos (Crane et al., 2012) and methyl parathion (Ellison et al., 2012a) to their more toxic oxon metabolites is mainly catalyzed by CYP2B6, a public health concern due to their worldwide use and documented human exposures (Ellison et al., 2012b). Further environmental substrates are the insecticide and endocrine disruptor methoxychlor, the extensively used insect repellent $N, N$-diethyl-m-toluamide (Das et al., 2008), profenofos and other pesticides (Abass and Pelkonen, 2012), as well as the tobacco-specific nitrosamine, 4-(methylnitrosamino)-1-(3-pyridyl)-1-butanone (NNK; Smith et al., 2003), aflatoxin B1 (Code et al., 1997), and others (Hodgson and Rose, 2007; Abass and Pelkonen, 2012).

Several structurally unrelated drugs have been shown to inhibit CYP2B6 and many of them do that in a mechanism-based, irreversible manner (Turpeinen et al., 2006; Turpeinen and Zanger, 2012). The thienopyridine derivatives clopidogrel and ticlopidine are prodrugs that selectively inhibit platelet aggregation and have been in clinical use for the prevention of atherothrombotic events for several years. Both of them are potent mechanismbased inhibitors of CYP2B6 (Richter et al., 2004; Zhang et al., 2011a). The established anticancer agent, thioTEPA $\left(N, N^{\prime}, N^{\prime \prime}\right.$ triethylenethiophosphoramide) was also found to be a highly selective and mechanism-based CYP2B6 inhibitor (Rae etal., 2002; Harleton etal., 2004; Richter etal., 2005). A comparison of several selective inhibitors revealed that 2-phenyl-2(1-piperidinyl)propane is probably the most selective CYP2B6 inhibitor in vitro (Walsky and Obach, 2007). Recent in vitro observations identified the progesterone receptor antagonist, mifepristone (RU486; Lin et al., 2009); the anti-Parkinsonian agent selegiline (the R-enantiomer of deprenyl; Sridar et al., 2012), methadone (Amunugama etal., 2012), and tamoxifen (Sridar etal., 2012) as potent mechanism-based inhibitors. In vivo drug-drug interactions have been reported, for example, between thioTEPA and cyclophosphamide (Huitema et al., 2000), clopidogrel and bupropion (Turpeinen et al., 2005a), voriconazole and efavirenz (Liu etal., 2008; Jeong et al., 2009), clopidogrel and efavirenz (Jiang et al., 2012), and between ticlopidine and ketamine (Peltoniemi et al., 2011). Furthermore, certain non-pharmaceutical compounds like particular benzylpyridine derivatives have been characterized as very potent inhibitors of CYP2B6 (Korhonen 
etal., 2007) and have been utilized for structural modeling experiments (Gay et al., 2010).

\section{PHARMACOGENETICS OF CYP2B6}

The CYPalleles website ${ }^{1}$ currently lists 37 distinct star-alleles, i.e., gene haplotypes with a distinct variant amino acid sequence or with demonstrated functional effect (last accessed: February 21st, 2013). More than 30 amino acid-changing single-nucleotide polymorphisms (SNPs) occur in different combinations and together with additional non-coding variants and many more SNPs not yet assigned to particular haplotypes. The worldwide variations in SNP frequencies have been reviewed recently (Li et al., 2012). Table 1 lists the most important variants in terms of frequency and functional impact and summarizes updated structural, functional, and frequency information for different ethnicities. In addition to the CYPallele website, further valuable information about CYP2B6 SNPs and pharmacogenetics are available on the websites of The Pharmacogenomics Knowledgebase ${ }^{2}$, the NCBI portal for short genetic variations, $\mathrm{dbSNP}^{3}$, the 1000 Genomes Catalog of Human Genetic Variation ${ }^{4}$, as well as the NHLBI exome sequencing project $^{5}$.

\footnotetext{
${ }^{1}$ http://www.cypalleles.ki.se/cyp2b6.htm

${ }^{2}$ http://www.pharmgkb.org/

${ }^{3}$ http://www.ncbi.nlm.nih.gov/projects/SNP/

${ }^{4}$ http://www.1000genomes.org/

${ }^{5}$ http://EVS.gs.washington.edu
}

\section{CYP2B6*6 AND EFAVIRENZ: IN VIVO, EX VIVO, IN VITRO}

The most common variant allele in all populations studied to date harbors two amino acid changes, Q172H and K262R, and is termed $C Y P 2 B 6^{*} 6$. This haplotype occurs in about 15 to over $60 \%$ of individuals, depending on ethnicity (Table 1). Although additional variants occur in the promoter and in introns, their functional impact appears to be of limited relevance and will not be further discussed here (Lamba et al., 2003; Hesse et al., 2004; Hofmann et al., 2008).

Since the discovery that CYP2B6 is the major enzyme for efavirenz 8-hydroxylation (Ward et al., 2003), pharmacogenetic studies have linked the Q172H variant to elevated plasma concentrations of efavirenz, indicating decreased enzyme function in vivo. This finding has been reproduced manifold in different ethnicities throughout the world (summarized by Telenti and Zanger, 2008; Rakhmanina and van den Anker, 2010). Three CYP2B6 polymorphisms, 15631G > T, 21011T > C, and an intron 3 SNP rs4803419, were also shown to be associated with efavirenz pharmacokinetics at genome wide significance (Holzinger et al., 2012).

The potent first-generation NNRTI of HIV-1 is recommended as initial therapy with two NRTIs in highly active antiretroviral therapy (HAART) regimes, but patients with subtherapeutic plasma concentrations can develop resistance and treatment failure, whereas those with too high plasma levels are at increased risk of central nervous system (CNS) side effects, which can lead to treatment discontinuation in a fraction of patients (King and Aberg, 2008). Q172H variant was furthermore associated

Table 1 | Summary data on selected genetic polymorphisms of CYP2B6.

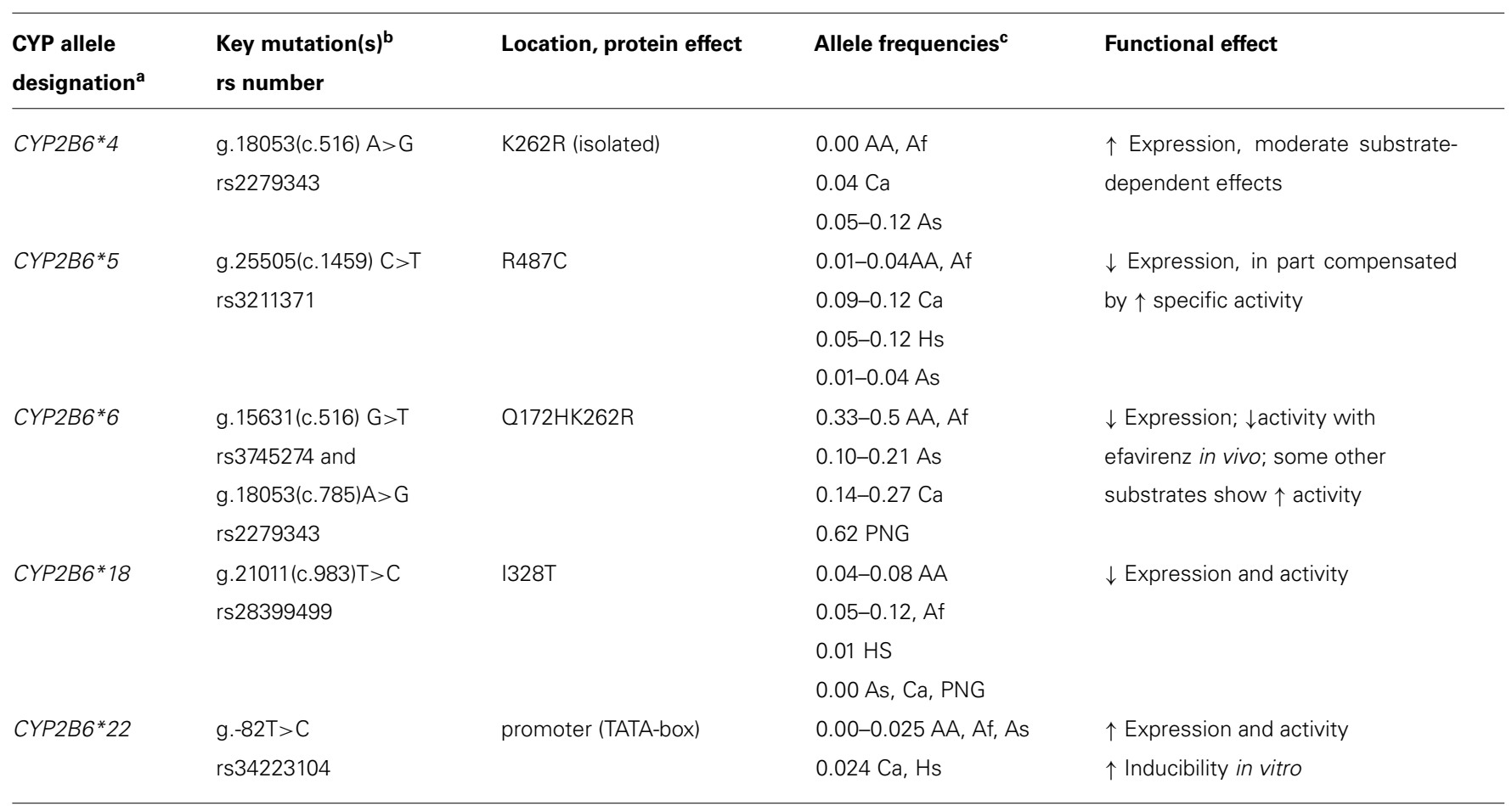

${ }^{a}$ According to CYPallele nomenclature homepage http://www.cypalleles. ki.se.

${ }^{b}$ Genomic (g.) and cDNA (c.) positions are given in bp.

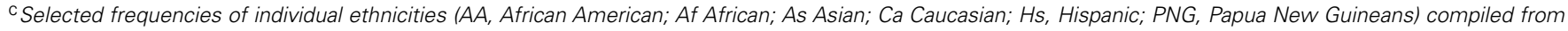
dbSNP http://www.ncbi.nlm.nih.gov/SNP and from the literature cited in the text. 
with increased neurotoxicity and other CNS side effects (Haas et al., 2004; King and Aberg, 2008; Lubomirov et al., 2010; Ribaudo etal., 2010; Maimbo etal., 2011) with HAART-induced liver injury (Yimer et al., 2011), and with efavirenz treatment discontinuation and the associated risk of developing drug resistance (Ribaudo et al., 2006; Lubomirov et al., 2011; Wyen et al., 2011). Importantly, compound heterozygotes of 516T and another low activity allele (e.g., ${ }^{\star} 11,{ }^{\star} 18,{ }^{\star} 27,{ }^{\star} 28$ ) also predict high efavirenz plasma levels (Rotger et al., 2007; Ribaudo et al., 2010). In prospective, genotype-based dose adjustment studies the therapeutic dose of efavirenz could be successfully reduced and CNS-related side effects decreased (Gatanaga et al., 2007; Gatanaga and Oka, 2009). Using pharmacokinetic modeling and simulation it was suggested that a priori dose reduction in homozygous $C Y P 2 B 6^{*} 6$ patients would maintain drug exposure within the therapeutic range in this group of patients (Nyakutira et al., 2008).

The in vitro data that have accumulated over the years on the $C Y P 2 B 6^{*} 6$ allele draw a more complex picture with functional consequences on various levels including pre-mRNA splicing, protein expression, as well as substrate-dependent changes in enzyme activity and different sensitivity toward irreversible inhibition. While early studies using recombinantly expressed enzyme variants found higher 7-ethoxycoumarin O-deethylase activity for the Q172H variant (Ariyoshi et al., 2001; Jinno et al., 2003), in genotyped human livers (ex vivo), the ${ }^{*} 6$ allele has been associated with approximately $50-75 \%$ decreased protein levels (Lang et al., 2001; Desta et al., 2007; Hofmann et al., 2008). An explanation for decreased protein expression was provided based on the observation that the c.516G $>$ T SNP coding for Q172H in exon 4 (rs3745274, Table 1) was correlated to increased amounts of a hepatic splice variant that lacked exons 4-6, and concurrently to decreased amounts of the normal functional transcript. Recombinant expression of minigene constructs in mammalian cells proved that the c.516G $>\mathrm{T}$ variant was causally involved in erroneous splicing and lower expression of functional mRNA and protein (Hofmann et al., 2008). It has been hypothesized that binding of splice factors to an exonic splicing enhancer(s) located in exon 4 could be affected by the variant (Zanger and Hofmann, 2008; Sadee et al., 2011). Although reduced expression in liver appears to satisfactorily explain increased efavirenz plasma concentrations in individuals with ${ }^{*} 6 /{ }^{*} 6$ genotype (Desta et al., 2007), recent in vitro data of expressed variants seem to indicate that the amino acid substitutions contribute to changes in catalytic activity of the enzyme. Structurally this is not easy to comprehend, because the Q172H and Lys262Arg amino acid changes occur in regions of the protein that are not directly located at the active site or that have been identified as substrate recognition sites (Figure 2).

Concerning efavirenz and also other substrates, the available in vitro data are however, not well in agreement with each other. Table 2 summarizes kinetic parameters for bupropion and efavirenz for CYP2B6 enzyme variants obtained from different recombinant expression systems. Using Escherichia coli expression system, Zhang et al. (2011b) purified six $N$-terminally truncated expressed variants to homogeneity and reconstituted them with NADPH:cytochrome 450 reductase (POR) at a molar ratio of 1:2

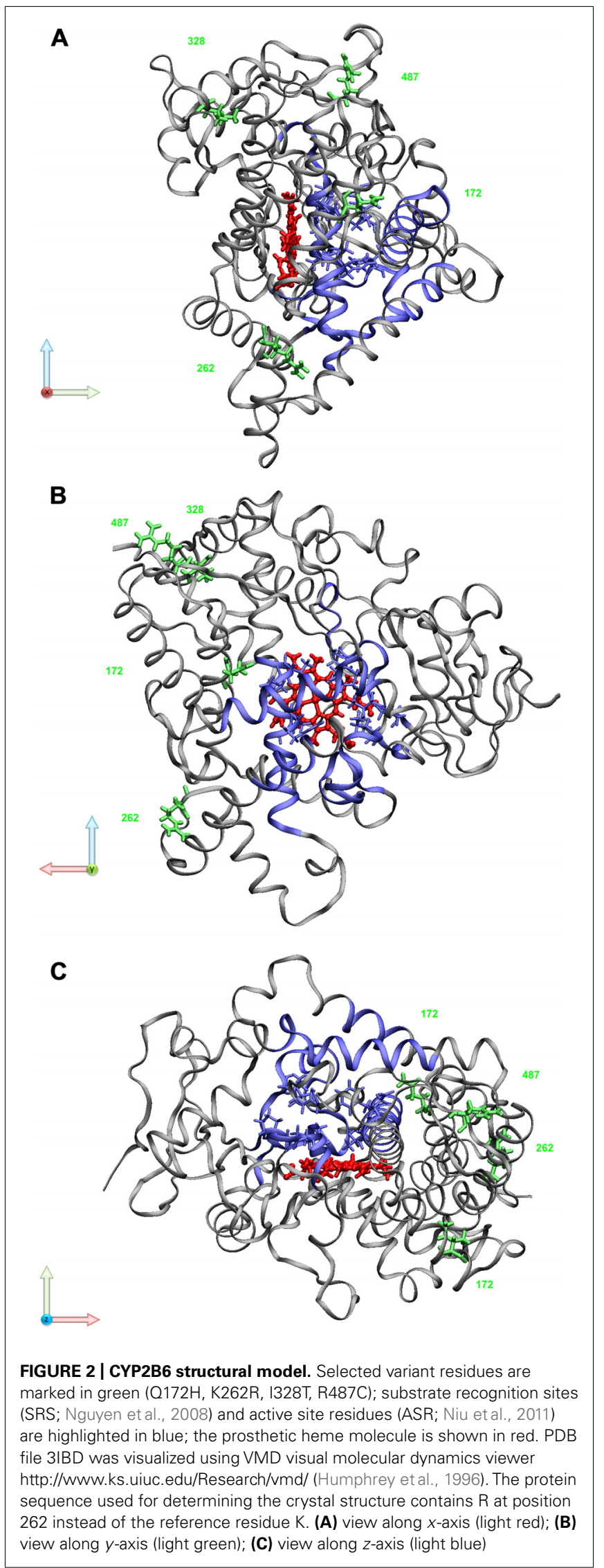


Table 2 | Kinetic properties of recombinantly expressed CYP2B6 protein variants with bupropion and efavirenz.

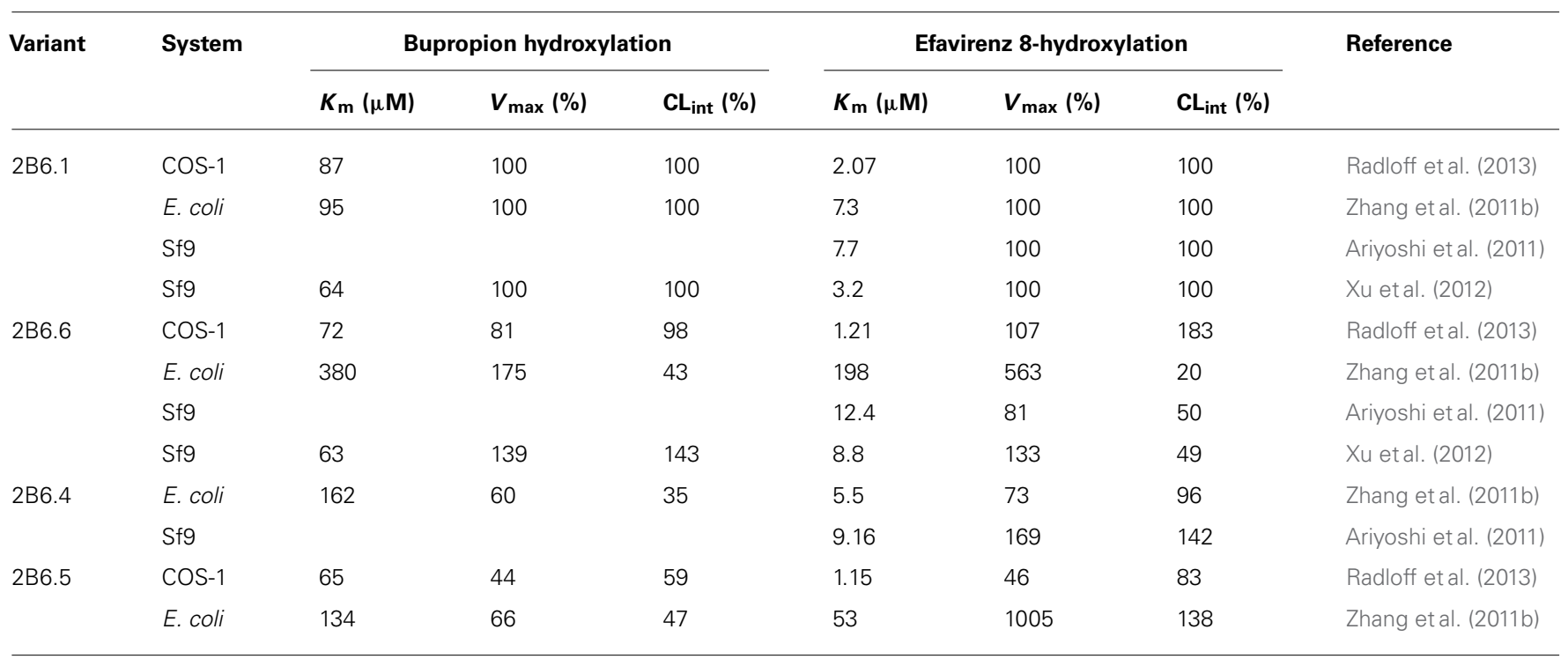

Only studies which determined kinetic parameters $\left(K_{m}, V_{\max }\right.$ or $\left.K_{\text {cat }}\right)$ were included.

and measured efavirenz and bupropion kinetics. Using Sf9 insect cell cotransfection, CYP2B6.1, 2B6.4 and 2B6.6 were expressed in the presence of 10-fold excess of POR, i.e., under saturating conditions, to measure efavirenz kinetics (Ariyoshi et al., 2011). Another study determined both bupropion and efavirenz kinetics in protein preparations also derived from insect cells in the presence or absence of cytochrome b5 (CYB5) but at somewhat more variable ratios in regard to POR (Xu et al., 2012). Radloff et al. (2013) used the COS-1 expression system, where P450 monooxygenase activity is supported by endogenously expressed POR, to determine bupropion and efavirenz kinetics for several novel CYP2B6 variants in comparison to the known variants $2 \mathrm{~B} 6.1,2 \mathrm{~B} 6.5$, and 2B6.6.

The compilation of data in Table 2 shows that differences between the variants were masked by differences between the expression systems. For example, efavirenz $K_{\mathrm{m}}$ was moderately decreased (58\%) for COS-1 cell-expressed 2B6.6 compared to 2B6.1 but moderately larger for both insect cell-expressed proteins. The E. coli-expressed variant showed, however, 27-fold increased $K_{\mathrm{m}}$. While the COS-1 proteins had almost identical $V_{\max }$, one of the insect cellproteins had decreased $V_{\max }(81 \%)$, while the other had increased activity (133\%). Again, the E. coli-expressed variant showed the biggest difference of almost sixfold higher activity for the variant. Similar discrepancies, albeit less dramatic, were found with bupropion as substrate (Table 2).

This data-comparison illustrates the problems that still exist with recombinant $\mathrm{P} 450$ expression systems, and particularly for CYP2B6, which appears to be an enzyme that sensibly reacts with activity changes to expression conditions. It is difficult to pin down the reasons for these differences exactly. Reconstitution of recombinant or even purified P450 with POR and CYB5 is a non-trivial problem especially if different protein variants shall be compared for quantitative kinetic parameters. Reconstitution under saturating conditions with respect to electron donators, e.g., at a POR:P450 ratio of 10 , is a straightforward practical way, but in hepatocytes, POR is stoichiometrically underrepresented (ratio about 1:10) and may be limiting for monooxygenase activity (Gomes et al., 2009). Enzyme variants may interact differently with the electron donors and catalytic differences could thus depend on reconstitution conditions. In addition, $N$-terminal modifications required to achieve high expression in $E$. coli may interact with the DNA-polymorphisms to be analyzed. In the COS-cell system, on the other hand, the POR:P450 ratio can neither be controlled nor quantified because expression of P450 is too low for spectral quantitation.

Taken together, the data from expression systems indicated that catalytic differences may exist between CYP2B6.6 and CYP2B6.1. However, except for the E. coli study, the differences were rather modest and at present it cannot be concluded with certainty whether the CYP2B6.6 variant is catalytically more or less active compared to the wild-type, atleast for bupropion and efavirenz. Taken all evidence together, the decrease in hepatic expression due to erroneous splicing caused by the c.516G > T SNP (Desta et al., 2007; Hofmann et al., 2008) most plausibly explains most of the phenotypic in vivo activity differences observed with efavirenz and bupropion.

CYP $2 B 6^{*} 6$ SNP-related functional differences were also observed with inhibitors. In contrast to the wild-type enzyme the recombinantly expressed $\mathrm{K} 262 \mathrm{R}$ variant was not inactivated by efavirenz, but both enzymes were irreversibly inhibited by 8 hydroxyefavirenz (Bumpus et al., 2006; Bumpus and Hollenberg, 2008). Lower susceptibility to inhibition of the K262R variant and the CYP2B6.6 double variant compared to CYP2B6.1 was also found with respect to sertraline and clopidogrel, as well as several other potent drug inhibitors of CYP2B6 (Talakad et al., 2009). These data indicate a role of genetic polymorphisms in drug-drug interaction sensitivity of CYP2B6, a finding that warrants further investigation in vivo. 


\section{OTHER CYP2B6 VARIANTS AND OTHER SUBSTRATES - IN VITRO STUDIES}

The two amino acid changes that together constitute the ${ }^{*} 6$ allele also occur in isolation, although at much lower frequencies (Klein et al., 2005; Zanger et al., 2007; Table 1). In most pharmacogenetic studies they are not being determined and functional data is therefore rare, especially concerning ${ }^{*}$ (Klein et al., 2005). Data from recombinant systems as well as liver data suggest that the K262R variant possesses catalytic activities similar to the wild-type enzyme, although with different substrates moderately increased or decreased activity was observed (Tables $\mathbf{2}$ and 3; Desta et al., 2007; Hofmann et al., 2008). The allele with amino acid change [R487C] in exon 9 ( ${ }^{*}$ variant; Table 1$)$ expresses very low levels of protein which does not translate into similarly reduced activities as measured with bupropion as well as efavirenz (Lang etal., 2001; Desta et al., 2007; Hofmann et al., 2008). The variant was shown to have higher specific activity compared to wild-type (Radloff et al., 2013). In human liver, this leads to partial compensation of low expression, finally resulting in a phenotype with moderately decreased activity with bupropion and efavirenz in vivo. This explains why CYP2B6*5 was not associated with efavirenz pharmacokinetics in HIV patients (Burger et al., 2006).

The second most important functionally deficient allele is CYP2B6 ${ }^{*} 18$ (c.983C $\left.>\mathrm{T}[\mathrm{I} 328 \mathrm{~T}]\right)$, which occurs predominantly in African subjects with allele frequencies of 4-11\% (Mehlotra etal., 2007; Li etal., 2012). The I328T variant expressed no detectable protein or activity toward bupropion, 7-ethoxy-4trifluoromethylcoumarin (7-EFC), selegiline and artemether in COS-1 cells whereas a partially defective protein was expressed in insect cells (Klein et al., 2005; Watanabe et al., 2010; Honda et al., 2011). This demonstrates another example for expression system-dependent differences. Most likely the $2 \mathrm{~B} 6.18$ variant is temperature-sensitive and thus able to be expressed at the lower temperature $\left(27^{\circ} \mathrm{C}\right)$ of insect cell culture but not at $37^{\circ} \mathrm{C}$. Interestingly, the $\mathrm{I} 328 \mathrm{~T}+\mathrm{Q} 172 \mathrm{H}$ double variant expressed partially functional protein in HEK293 cells and in yeast (Wang etal., 2006), indicating that Q172H can stabilize the I328T variant. The ${ }^{*} 18$ allele is thus phenotypically a null allele, at least in vitro with some substrates. This is supported by many in vivo studies (see below).

At least 12 additional null or low-activity alleles have been described and analyzed with various substrates (Lang et al., 2004; Klein et al., 2005; Rotger et al., 2007; Watanabe et al., 2010; Honda et al., 2011). Although they are rather rare in all investigated populations they may have profound effects on drug metabolism if present in compound heterozygous genotypes, e.g., in combination with ${ }^{\star} 6$ or ${ }^{\star} 18$ (Rotger et al., 2007). The CYP $2 B 6^{\star} 22$ allele is a gain-of-function variant associated with increased transcription in vitro (Zukunft et al., 2005) and with increased activity in vivo (Rotger et al., 2007). It was shown that a $-82 \mathrm{~T}>\mathrm{C}$ exchange alters the TATA-box into a functional CCAAT/enhancer-binding protein binding site that causes increased transcription from an alternative downstream initiation site (Zukunft et al., 2005). Interestingly, the $-82 \mathrm{~T}>\mathrm{C}$ polymorphism also confers synergistically enhanced CYP2B6 inducibility by the PXR ligand rifampicin in human primary hepatocytes (Li et al., 2010).

New variants are discovered preferentially in previously uncharacterized ethnic groups. Restrepo et al. (2011) described two novel combinations of known amino acid variants in a Colombian population. Structural variants including a novel CYP2B6/2B7P1 duplicated fusion allele $\left(C Y P 2 B 6^{*} 30\right)$ were found when individuals from various ethnicities were screened for copy number variations (Martis etal., 2012). Furthermore, three novel and five previously uncharacterized amino acid variants in different combinations $\left(C Y P 2 B 6^{\star} 33\right.$ to $\left.{ }^{\star} 37\right)$ were identified by resequencing the CYP2B6 gene in a Rwandese cohort of HIV-1-infected patients (Radloff et al., 2013). The variants were then functionally studied by COS-1 cell expression and by in silico prediction tools. At least four of the variants were shown to result in complete or almost complete loss of function with bupropion and efavirenz as substrates. The detailed comparison of in vitro functionality of the variants with in silico prediction tools including a thorough substrate docking simulation analysis points at the challenge to deal with the hundreds of new variants that exist in all populations as currently uncovered by next generation sequencing approaches and large scale population projects (see links above).

Table 3 | Properties of recombinantly expressed CYP2B6 protein variants with other clinical substrates.

\begin{tabular}{|c|c|c|c|c|c|c|c|c|c|c|}
\hline \multirow[b]{2}{*}{ Variant } & \multicolumn{2}{|c|}{$\begin{array}{l}\text { Artemether }{ }^{1} \\
\text { CoS-7 cells } \\
\text { (Honda et al., 2011) }\end{array}$} & \multicolumn{2}{|c|}{$\begin{array}{l}\text { Selegiline }^{2} \\
\text { COS-7 cells } \\
\text { (Watanabe et al., 2010) }\end{array}$} & \multicolumn{2}{|c|}{$\begin{array}{l}\text { Chlorpyrifos }^{3} \\
\text { COS-1 cells } \\
\text { (Crane et al., 2012) }\end{array}$} & \multicolumn{2}{|c|}{$\begin{array}{l}\text { Cyclophosphamide }^{4} \\
\text { Sf9 cells } \\
\text { (Ariyoshi et al., 2011) }\end{array}$} & \multicolumn{2}{|c|}{$\begin{array}{l}\text { Cyclophosphamide } 4 \\
\text { E. coli } \\
\text { (Raccor et al., 2012) }\end{array}$} \\
\hline & $K_{\mathrm{m}}(\mu \mathrm{M})$ & $V_{\max }(\%)$ & $K_{\mathrm{m}}(\mu \mathrm{M})$ & $V_{\max }(\%)$ & $K_{\mathrm{m}}(\mu \mathrm{M})$ & $V_{\max }(\%)$ & $K_{\mathrm{m}}(\mathrm{mM})$ & $V_{\max }(\%)$ & $K_{\mathrm{m}}(\mathrm{mM})$ & $V_{\max }(\%)$ \\
\hline 2B6. 1 & 3.1 & 100 & 48.2 & 100 & 1.84 & 100 & 2.68 & 100 & 3.6 & 100 \\
\hline 2B6.6 & 6.72 & 416 & 56.6 & 169 & 1.97 & 254 & 1.62 & 99 & 4.0 & 155.2 \\
\hline 2B6.4 & 2.73 & 196 & 45.8 & 147 & 1.09 & 1094 & 2.75 & 74 & 3.5 & 67.1 \\
\hline 2B6.5 & 6.87 & 55 & 70.1 & 85 & 0.80 & 441 & & & 5.1 & 72.4 \\
\hline
\end{tabular}

${ }^{1}$ O-Demethylation.

${ }^{2} \mathrm{~N}$-Demethylation (mean values were calculated for several expressions of CYP2B6.1).

${ }^{3}$ Desulfation.

4-Hydroxylation. 


\section{CLINICAL STUDIES WITH DIFFERENT DRUGS}

The widely used anticancer and immunosuppressant prodrug cyclophosphamide depends on bioactivation to 4hydroxycyclophosphamide for cytotoxic activity. Bioactivation is highly variable in cancer patients and has been attributed mainly to CYP2B6 in vitro and in vivo with contributions from CYP2C19 and CYP3A4 (Chang et al., 1993; Raccor et al., 2012). The case of cyclophosphamide 4-hydroxylation deserves particular attention, as it exemplifies substrate-dependent effects of CYP2B6 pharmacogenetics. Cyclophosphamide 4-hydroxylation was initially reported to be enhanced in livers genotyped $\mathrm{CYP} 2 B 6^{*} 6 /{ }^{*} 6$ (Xie etal., 2003), which was confirmed in several later in vivo studies (Xie etal., 2006; Nakajima etal., 2007; Torimoto and Kohgo, 2008). However, other in vivo studies analyzing pharmacokinetics or clinical outcome also presented contradictory or negative results (Singh et al., 2007; Ekhart et al., 2008; Melanson et al., 2010; Yao et al., 2010; Raccor et al., 2012). In vitro, insect cell-expressed recombinant CYP2B6.4 [K262R] had lower activity for cyclophosphamide 4-hydroxylation (Ariyoshi et al., 2011; Raccor et al., 2012). The CYP2B6.4 and CYP2B6.6 variants thus display mirror-inverted catalytic activities toward efavirenz and cyclophosphamide, in that the former variant is the catalytically more active one with efavirenz, whereas the opposite is true for the latter variant (Table 3). A direct comparison of catalytic properties of the two variants with the reference enzyme expressed in insect cells supports this inverse behavior of the two variants toward these two substrates (Ariyoshi et al., 2011). Interestingly, several studies associated other variants including $C Y P 2 B 6^{\star} 4,{ }^{*} 5,{ }^{*} 8$, and ${ }^{\star} 9$ with lower 4-OH cyclophosphamide formation in vivo or with worse outcome (Takada et al., 2004; Bray et al., 2010; Helsby et al., 2010; Joy et al., 2012). Taken together, the data concerning cyclophosphamide from both in vivo and in vitro indicate that CYP2B6 polymorphism plays a role, although the studies are so far not yet conclusive. This may be explained by different study size design as well as lack of consistency in allele definition and genotype information among studies (Helsby and Tingle, 2011).

In addition to efavirenz, CYP2B6 genotype also affects plasma levels of the antiretroviral drug nevirapine (Penzak et al., 2007; Mahungu et al., 2009). The impact of the CYP2B6 516G $>$ T polymorphism on nevirapine exposure was confirmed and quantified in a pharmacometric analysis of nevirapine plasma concentrations

\section{REFERENCES}

Abass, K., and Pelkonen, O. (2012). The inhibition of major human hepatic cytochrome P450 enzymes by 18 pesticides: comparison of the $\mathrm{N}$-in-one and single substrate approaches. Toxicol. In Vitro doi: 10.1016/j.tiv.2012.05.003 [Epub ahead of print].

Amunugama, H., Zhang, H., and Hollenberg, P. F. (2012). Mechanismbased inactivation of cytochrome P450 2B6 by methadone through destruction of prosthetic heme. Drug Metab. Dispos. 40, 1765-1770.

Ariyoshi, N., Miyazaki, M., Toide,

K., Sawamura Yi, and Kamataki,

T. (2001). A single nucleotide polymorphism of CYP2b6 found in Japanese enhances catalytic activity by autoactivation. Biochem. Biophys. Res. Commun. 281, 1256-1260. Afuso, S., Kumamoto, T., Nakamura, H., et al. (2011). Q172H replacement overcomes effects on the metabolism of cyclophosphamide and efavirenz caused by CYP2B6 variant with Arg262. Drug Metab. Dispos. 39, 2045-2048.

Asimus, S., and Ashton, M. (2009). Artemisinin - a possible CYP2B6 probe substrate? Biopharm. Drug Dispos. 30, 265-275.

Bray, J., Sludden, J., Griffin, M. J., Cole, M., Verrill, M., Jamieson, D.,
Ariyoshi, N., Ohara, M., Kaneko, M.

from 271 patients genotyped for 198 SNPs in 45 ADME (absorption, distribution, metabolism, and excretion) genes and covariates (Lehr et al., 2011). Moreover, nevirapine-related cutaneous adverse events, which are most likely major histocompatibility complex (MHC) class I-mediated, were significantly influenced by CYP2B6 polymorphism while hepatic side effects, most likely MHC class II-mediated, were unaffected by CYP2B6 (Yuan et al., 2011).

CYP2B6 allele variants were also investigated in the context of the synthetic $\mu$-opioid receptor agonist, methadone, which is metabolized by CYPs 3A4/5, 2B6, and 2D6, and used as a maintenance treatment for opioid addiction. In ${ }^{*} 6 /{ }^{*} 6$ carriers $(S)$-methadone plasma levels were increased leading to potentially higher risk of severe cardiac arrhythmias and methadone associated deaths (Crettol et al., 2005; Eap et al., 2007; Bunten et al., 2011). Methadone dose requirement for effective treatment of opioid addiction was shown to be significantly reduced in carriers of this genotype (Levran et al., 2011).

\section{CONCLUSION}

The polymorphism of the CYP2B6 gene has initially been studied by reverse genetics approach, i.e., starting from the identification of genetic variants in DNA and liver samples, followed by in vitro characterization of genotyped livers and expressed variant proteins. Clinical studies have then contributed to identify the variants that are important in vivo, and in vitro studies are again needed to identify and mechanistically explain causal variants. Nevertheless, CYP2B6 pharmacogenetics has yet to be fully explored, especially with respect to combined effects of the involved variants on both expression and catalytic properties, the latter of which additionally depend on the substrate. While the relevance for HIV-1 therapy with efavirenz is well established and translational approaches have already been clinically tested, an increasing number of studies suggest clinical relevance for additional drug substrates.

\section{ACKNOWLEDGMENTS}

Work in the authors' laboratory was supported by the German Federal Ministry of Education and Research (Virtual Liver Network grant 0315755), the 7FP EU Initial Training Network program, FightingDrugFailure' (GA-2009-238132), and by the Robert-Bosch Foundation, Stuttgart, Germany.

et al. (2010). Influence of pharmacogenetics on response and toxicity in breast cancer patients treated with doxorubicin and cyclophosphamide. Br. J. Cancer 102, $1003-$ 1009.

Bumpus, N. N., and Hollenberg, P. F. (2008). Investigation of the mechanisms underlying the differential effects of the K262R mutation of P450 2B6 on catalytic activity. Mol. Pharmacol. 74, 990-999.

Bumpus, N. N., Kent, U. M., and Hollenberg, P. F. (2006). Metabolism of efavirenz and 8-hydroxyefavirenz by P450 2B6 leads to inactivation by two distinct mechanisms. J. Pharmacol. Exp. Ther. 318, 345-351.
Bunten, H., Liang, W.-J., Pounder, D., Seneviratne, C., and Osselton, M. D. (2011). CYP2B6 and OPRM1 gene variations predict methadone-related deaths. Addict. Biol. 16, 142-144.

Burger, D., van der Heiden, I., la Porte, C., van der Ende, M., Groeneveld, P., Richter, C., et al. (2006). Interpatient variability in the pharmacokinetics of the HIV non-nucleoside reverse transcriptase inhibitor efavirenz: the effect of gender, race, and CYP2B6 polymorphism. Br. J. Clin. Pharmacol. 61, 148-154.

Burk, O., Arnold, K. A., Nussler, A. K., Schaeffeler, E., Efimova, E., Avery, B. A., etal. (2005). Antimalarial artemisinin drugs induce 
cytochrome P450 and MDR1 expression by activation of xenosensors pregnane $\mathrm{X}$ receptor and constitutive androstane receptor. Mol. Pharmacol. 67, 1954-1965.

Chang, T. K., Weber, G. F., Crespi, C. L., and Waxman, D. J. (1993). Differential activation of cyclophosphamide and ifosphamide by cytochromes $\mathrm{P}$ $4502 \mathrm{~B}$ and $3 \mathrm{~A}$ in human liver microsomes. Cancer Res. 53, 5629-5637.

Choudhary, D., Jansson, I., Schenkman, J. B., Sarfarazi, M., and Stoilov, I. (2003). Comparative expression profiling of 40 mouse cytochrome P450 genes in embryonic and adult tissues. Arch. Biochem. Biophys. 414, 91-100.

Code, E. L., Crespi, C. L., Penman, B. W., Gonzalez, F. J., Chang, T. K., and Waxman, D. J. (1997). Human cytochrome P4502B6: interindividual hepatic expression, substrate specificity, and role in procarcinogen activation. Drug Metab. Dispos. 25, 985-993.

Court, M. H., Duan, S. X., Hesse, L. M., Venkatakrishnan, K., and Greenblatt, D. J. (2001). Cytochrome P-450 2B6 is responsible for interindividual variability of propofol hydroxylation by human liver microsomes. Anesthesiology 94, 110-119.

Crane, A. L., Klein, K., and Olson, J. R. (2012). Bioactivation of chlorpyrifos by CYP2B6 variants. Xenobiotica 42 , 1255-1262.

Crettol, S., Déglon, J.-J., Besson, J., Croquette-Krokkar, M., Gothuey, I., Hämmig, R., et al. (2005). Methadone enantiomer plasma levels, CYP2B6, CYP2C19, and CYP2C9 genotypes, and response to treatment. Clin. Pharmacol. Ther. 78 593-604.

Croom, E. L., Stevens, J. C., Hines, R. N., Wallace, A. D., and Hodgson, E. (2009). Human hepatic CYP2B6 developmental expression: the impact of age and genotype. Biochem. Pharmacol. 78, 184-190.

Das, P. C., Cao, Y., Rose, R. L., Cherrington, N., and Hodgson, E. (2008). Enzyme induction and cytotoxicity in human hepatocytes by chlorpyrifos and $N, N$-diethyl- $m$-toluamide (DEET). Drug Metab. Drug Interact. 23, 237-260.

Desta, Z., Moaddel, R., Ogburn, E. T., $\mathrm{Xu}$, C., Ramamoorthy, A., Venkata, S. L. V., et al. (2012). Stereoselective and regiospecific hydroxylation of ketamine and norketamine. Xenobiotica 42, 1076-1087

Desta, Z., Saussele, T., Ward, B., Blievernicht, J., Li, L., Klein, K., et al. (2007). Impact of CYP2B6 polymorphism on hepatic efavirenz metabolism in vitro. Pharmacogenomics 8, 547-558.
Dutheil, F., Beaune, P., and Loriot, M.-A. (2008). Xenobiotic metabolizing enzymes in the central nervous system: contribution of cytochrome P450 enzymes in normal and pathological human brain. Biochimie 90, 426-436.

Eap, C. B., Crettol, S., Rougier, J.S., Schläpfer, J., Sintra Grilo, L., Déglon, J.-J., et al. (2007). Stereoselective block of hERG channel by (S)-methadone and QT interval prolongation in CYP2B6 slow metabolizers. Clin. Pharmacol. Ther. 81 719-728.

Ekhart, C., Doodeman, V. D., Rodenhuis, S., Smits, P. H. M., Beijnen, J H., and Huitema, A. D. R. (2008). Influence of polymorphisms of drug metabolizing enzymes (CYP2B6, CYP2C9, CYP2C19, CYP3A4 CYP3A5, GSTA1, GSTP1, ALDH1A1 and ALDH3A1) on the pharmacokinetics of cyclophosphamide and 4-hydroxycyclophosphamide. Pharmacogenet. Genomics 18 515-523.

Ekins, S., Vandenbranden, M., Ring, B. J., Gillespie, J. S., Yang, T. J., Gelboin, H. V., et al. (1998). Further characterization of the expression in liver and catalytic activity of CYP2B6. J. Pharmacol. Exp. Ther. 286, 1253-1259.

Ekins, S., and Wrighton, S. A. (1999). The role of CYP2B6 in human xenobiotic metabolism. Drug Metab. Rev. 31, 719-754.

Ellison, C. A., Tian, Y., Knaak, J. B., Kostyniak, P. J., and Olson, J. R. (2012a). Human hepatic cytochrome p450-specific metabolism of the organophosphorus pesticides methyl parathion and diazinon. Drug Metab. Dispos. 40, 1-5.

Ellison, C. A., Abou El-Ella, S. S., Tawfik, M., Lein, P. J., and Olson, J. R. (2012b). Allele and genotype frequencies of CYP2B6 and CYP2C19 polymorphisms in Egyptian agricultural workers. J. Toxicol. Environ. Health A. 75, 232-241.

Erickson, D. A., Mather, G., Trager, W. F., Levy, R. H., and Keirns, J. J. (1999). Characterization of the in vitro biotransformation of the HIV-1 reverse transcriptase inhibitor nevirapine by human hepatic cytochromes P-450. Drug Metab. Dispos. 27, 1488-1495.

Faucette, S. R., Hawke, R. L., Lecluyse, E. L., Shord, S. S., Yan, B., Laethem, R. M., et al. (2000). Validation of bupropion hydroxylation as a selective marker of human cytochrome P450 2B6 catalytic activity. Drug Metab. Dispos. 28, 1222-1230.

Faucette, S. R., Wang, H., Hamilton, G. A., Jolley, S. L., Gilbert, D., Lindley, C., et al. (2004). Regulation of
CYP2B6 in primary human hepatocytes by prototypical inducers. Drug Metab. Dispos. 32, 348-358.

Faucette, S. R., Zhang, T.-C., Moore, R., Sueyoshi, T., Omiecinski, C. J., LeCluyse, E. L., et al. (2007). Relative activation of human pregnane $\mathrm{X}$ receptor versus constitutive androstane receptor defines distinct classes of CYP2B6 and CYP3A4 inducers. J. Pharmacol. Exp. Ther. 320, 72-80.

Feidt, D. M., Klein, K., Hofmann, U., Riedmaier, S., Knobeloch, D. Thasler, W. E., et al. (2010). Profiling induction of cytochrome p450 enzyme activity by statins using a new liquid chromatography-tandem mass spectrometry cocktail assay in human hepatocytes. Drug Metab. Dispos. 38, 1589-1597.

Ferguson, C. S., and Tyndale, R. F. (2011). Cytochrome P450 enzymes in the brain: emerging evidence of biological significance. Trends Pharmacol. Sci. 32, 708-714.

Fuhr, U., Jetter, A., and Kirchheiner, J. (2007). Appropriate phenotyping procedures for drug metabolizing enzymes and transporters in humans and their simultaneous use in the "cocktail" approach. Clin. Pharmacol. Ther. 81, 270-283.

Gatanaga, H., Hayashida, T., Tsuchiya, K., Yoshino, M., Kuwahara, T. Tsukada, H., etal. (2007). Successful efavirenz dose reduction in HIV type 1-infected individuals with cytochrome P450 2B6 *6 and ${ }^{*} 26$. Clin. Infect. Dis. 45, 1230-1237.

Gatanaga, H., and Oka, S. (2009). Successful genotype-tailored treatment with small-dose efavirenz. AIDS 23, 433-434.

Gay, S. C., Shah, M. B., Talakad, J. C., Maekawa, K., Roberts, A. G., Wilderman, P. R., et al. (2010). Crystal structure of a cytochrome P450 2B6 genetic variant in complex with the inhibitor 4-(4-chlorophenyl) imidazole at 2.0-A resolution. Mol. Pharmacol. 77, 529-538.

Gervot, L., Rochat, B., Gautier, J. C., Bohnenstengel, F., Kroemer, H., de Berardinis, V., et al. (1999). Human CYP2B6: expression, inducibility and catalytic activities. Pharmacogenetics 9, 295-306.

Gomes, A. M., Winter, S., Klein, K., Turpeinen, M., Schaeffeler, E., Schwab, M., et al. (2009) Pharmacogenomics of human liver cytochrome $\mathrm{P} 450$ oxidoreductase: multifactorial analysis and impact on microsomal drug oxidation. Pharmacogenomics 10, 579-599.

Goodwin, B., Moore, L. B., Stoltz, C. M., McKee, D. D., and Kliewer, S.
A. (2001). Regulation of the human CYP2B6 gene by the nuclear pregnane X receptor. Mol. Pharmacol. 60, 427-431.

Haas, D. W., Ribaudo, H. J., Kim, R. B., Tierney, C., Wilkinson, G. R., Gulick, R. M., et al. (2004). Pharmacogenetics of efavirenz and central nervous system side effects: an Adult AIDS Clinical Trials Group study. AIDS 18, 2391-2400.

Habtewold, A., Amogne, W., Makonnen, E., Yimer, G., Riedel, K.-D., Ueda, N., et al. (2011). Long-term effect of efavirenz autoinduction on plasma/peripheral blood mononuclear cell drug exposure and CD4 count is influenced by UGT2B7 and CYP2B6 genotypes among HIV patients. J. Antimicrob. Chemother. 66, 2350-2361.

Harleton, E., Webster, M., Bumpus, N. N., Kent, U. M., Rae, J. M., and Hollenberg, P. F. (2004). Metabolism of $N, N^{\prime}, N^{\prime \prime}$ triethylenethiophosphoramide by CYP2B1 and CYP2B6 results in the inactivation of both isoforms by two distinct mechanisms. J. Pharmacol. Exp. Ther. 310, 1011-1019.

Helsby, N., and Tingle, M. (2011). The importance of correct assignment of CYP2B6 genetic variants with respect to cyclophosphamide metabolizer status. Am. J. Hematol. 86, 383-384; author reply 384.

Helsby, N. A., Hui, C.-Y., Goldthorpe, M. A., Coller, J. K., Soh, M. C., Gow, P. J., et al. (2010). The combined impact of CYP2C19 and CYP2B6 pharmacogenetics on cyclophosphamide bioactivation. Br. J. Clin. Pharmacol. 70, 844-853.

Hesse, L. M., He, P., Krishnaswamy, S., Hao, Q., Hogan, K., von Moltke, L. L., et al. (2004). Pharmacogenetic determinants of interindividual variability in bupropion hydroxylation by cytochrome P450 2B6 in human liver microsomes. Pharmacogenetics 14, 225-238.

Hesse, L. M., Venkatakrishnan, K., Court, M. H., von Moltke, L. L., Duan, S. X., Shader, R. I., et al. (2000). CYP2B6 mediates the in vitro hydroxylation of bupropion: potential drug interactions with other antidepressants. Drug Metab. Dispos. 28, 1176-1183.

Hodgson, E., and Rose, R. L. (2007). The importance of cytochrome P450 2B6 in the human metabolism of environmental chemicals. Pharmacol. Ther. 113, 420-428.

Hoffman, S. M., Nelson, D. R., and Keeney, D. S. (2001). Organization, structure and evolution of the CYP2 gene cluster on human chromosome 
19. Pharmacogenetics $11,687-$ 698.

Hofmann, M. H., Blievernicht, J. K., Klein, K., Saussele, T., Schaeffeler, E., Schwab, M., et al. (2008). Aberrant splicing caused by single nucleotide polymorphism c.516G $>\mathrm{T}[\mathrm{Q} 172 \mathrm{H}]$, a marker of $\mathrm{CYP} 2 \mathrm{~B} 66^{\star} 6$, is responsible for decreased expression and activity of CYP2B6 in liver. J. Pharmacol. Exp. Ther. 325, 284-292.

Holzinger, E. R., Grady, B., Ritchie, M. D., Ribaudo, H. J., Acosta, E. P., Morse, G. D., et al. (2012). Genome-wide association study of plasma efavirenz pharmacokinetics in AIDS Clinical Trials Group protocols implicates several CYP2B6 variants. Pharmacogenet. Genomics 22, 858-867.

Honda, M., Muroi, Y., Tamaki, Y., Saigusa, D., Suzuki, N., Tomioka, Y., et al. (2011). Functional characterization of CYP2B6 allelic variants in demethylation of antimalarial artemether. Drug Metab. Dispos. 39, 1860-1865.

Hsyu, P. H., Singh, A., Giargiari, T. D., Dunn, J. A., Ascher, J. A., and Johnston, J. A. (1997). Pharmacokinetics of bupropion and its metabolites in cigarette smokers versus nonsmokers. J. Clin. Pharmacol. 37, 737-743.

Huang, Z., Roy, P., and Waxman, D. J. (2000). Role of human liver microsomal CYP3A4 and CYP2B6 in catalyzing $\mathrm{N}$-dechloroethylation of cyclophosphamide and ifosfamide. Biochem. Pharmacol. 59, 961-972.

Huitema, A. D., Kerbusch, T., Tibben, M. M., Rodenhuis, S., and Beijnen, J. H. (2000). Reduction of cyclophosphamide bioactivation by thioTEPA: critical sequencedependency in high-dose chemotherapy regimens. Cancer Chemother. Pharmacol. 46, 119-127.

Humphrey, W., Dalke, A., and Schulten, K. (1996). VMD: visual molecular dynamics. J. Mol. Graph. 14, 33-38, 27-28.

Jeong, S., Nguyen, P. D., and Desta, Z. (2009). Comprehensive in vitro analysis of voriconazole inhibition of eight cytochrome P450 (CYP) enzymes: major effect on CYPs 2B6, 2C9, 2C19, and 3A. Antimicrob. Agents Chemother. 53, 541-551.

Jiang, F., Desta, Z., Shon, J.-H., Yeo, C.-W., Kim, H.-S., Liu, K.H., et al. (2012). Effects of clopidogrel and itraconazole on the disposition of efavirenz and its hydroxyl-metabolites: exploration of a novel CYP2B6 phenotyping index. Br. J. Clin. Pharmacol. 75, 244-253.

Jinno, H., Tanaka-Kagawa, T., Ohno, A., Makino, Y., Matsushima, E., Hanioka,
N., et al. (2003). Functional characterization of cytochrome P450 2B6 allelic variants. Drug Metab. Dispos. 31, 398-403.

Joy, M. S., La, M., Wang, J., Bridges, A. S., Hu, Y., Hogan, S. L., et al. (2012). Cyclophosphamide and 4-hydroxycyclophosphamide pharmacokinetics in patients with glomerulonephritis secondary to lupus and small vessel vasculitis. $\mathrm{Br}$. J. Clin. Pharmacol. 74, 445-455.

Kharasch, E. D., Mitchell, D., Coles, R., and Blanco, R. (2008). Rapid clinical induction of hepatic cytochrome P4502B6 activity by ritonavir. Antimicrob. Agents Chemother. 52, 1663-1669.

King, J., and Aberg, J. A. (2008). Clinical impact of patient population differences and genomic variation in efavirenz therapy. AIDS 22, 1709 1717.

Klein, K., Lang, T., Saussele, T., BarbosaSicard, E., Schunck, W.-H., Eichelbaum, M., etal. (2005). Genetic variability of CYP2B6 in populations of African and Asian origin: allele frequencies, novel functional variants, and possible implications for antiHIV therapy with efavirenz. Pharmacogenet. Genomics 15, 861-873.

Ko, J. W., Desta, Z., and Flockhart, D. A. (1998). Human N-demethylation of (S)-mephenytoin by cytochrome P450s 2C9 and 2B6. Drug Metab. Dispos. 26, 775-778.

Korhonen, L. E., Turpeinen, M., Rahnasto, M., Wittekindt, C., Poso, A., Pelkonen, O., et al. (2007). New potent and selective cytochrome P450 2B6 (CYP2B6) inhibitors based on three-dimensional quantitative structure-activity relationship (3DQSAR) analysis. Br. J. Pharmacol. 150, 932-942.

Kreth, K., Kovar, K., Schwab, M., and Zanger, U. M. (2000). Identification of the human cytochromes P450 involved in the oxidative metabolism of "Ecstasy"-related designer drugs. Biochem. Pharmacol. 59, 1563 1571.

Lamba, V., Lamba, J., Yasuda, K., Strom, S., Davila, J., Hancock, M. L., et al. (2003). Hepatic CYP2B6 expression: gender and ethnic differences and relationship to CYP2B6 genotype and CAR (constitutive androstane receptor) expression. J. Pharmacol. Exp. Ther. 307, 906-922.

Lang, T., Klein, K., Fischer, J., Nüssler, A. K., Neuhaus, P., Hofmann, U., et al. (2001). Extensive genetic polymorphism in the human CYP2B6 gene with impact on expression and function in human liver. Pharmacogenetics 11, 399-415.
Lang, T., Klein, K., Richter, T., Zibat, A., Kerb, R., Eichelbaum, M., et al. (2004). Multiple novel nonsynonymous CYP2B6 gene polymorphisms in Caucasians: demonstration of phenotypic null alleles. J. Pharmacol. Exp. Ther. 311, 34-43.

Leclerc, J., Tournel, G., CourcotNgoubo Ngangue, E., Pottier, N. Lafitte, J.-J., Jaillard, S., et al. (2010). Profiling gene expression of whole cytochrome P450 superfamily in human bronchial and peripheral lung tissues: differential expression in non-small cell lung cancers. Biochimie 92, 292-306.

Lehr, T., Yuan, J., Hall, D., ZimdahlGelling, H., Schaefer, H. G., Staab, A., et al. (2011). Integration of absorption, distribution, metabolism, and elimination genotyping data into a population pharmacokinetic analysis of nevirapine. Pharmacogenet. Genomics 21, 721-730.

Levran, O., Peles, E., Hamon, S., Randesi, M., Adelson, M., and Kreek, M. J. (2011). CYP2B6 SNPs are associated with methadone dose required for effective treatment of opioid addiction. Addict. Biol. doi: 10.1111/j.1369-1600.2011.00349.x. [Epub ahead of print]

Lewis, D. F., Lake, B. G., Dickins, M., Eddershaw, P. J., Tarbit, M. H., and Goldfarb, P. S. (1999). Molecular modelling of CYP2B6, the human CYP2B isoform, by homology with the substrate-bound CYP102 crystal structure: evaluation of CYP2B6 substrate characteristics, the cytochrome b5 binding site and comparisons with CYP2B1 and CYP2B4. Xenobiotica 29, 361-393.

Lewis, D. F. V., Lake, B. G., and Dickins, M. (2004). Substrates of human cytochromes P450 from families CYP1 and CYP2: analysis of enzyme selectivity and metabolism. Drug Metab. Drug Interact. 20, 111-142.

Li, H., Ferguson, S. S., and Wang, H. (2010). Synergistically enhanced CYP2B6 inducibility between a polymorphic mutation in CYP2B6 promoter and pregnane $\mathrm{X}$ receptor activation. Mol. Pharmacol. 78, 704-713.

Li, J., Menard, V., Benish, R. L., Jurevic, R. J., Guillemette, C., Stoneking, M., etal. (2012). Worldwide variation in human drug-metabolism enzyme genes CYP2B6 and UGT2B7: implications for HIV/AIDS treatment. Pharmacogenomics 13 555-570.

Lin, H. L., Zhang, H., and Hollenberg, P. F. (2009). Metabolic activation of mifepristone (RU486) by mammalian P450s and the mechanism-based inactivation of human CYP2B6. J. Pharmacol. Exp. Ther. 329, 26-37.

Liu, P., Foster, G., LaBadie, R. R., Gutierrez, M. J., and Sharma, A. (2008). Pharmacokinetic interaction between voriconazole and efavirenz at steady state in healthy male subjects. J. Clin. Pharmacol. 48, 73-84.

Lubomirov, R., Colombo, S., di Iulio, J., Ledergerber, B., Martinez, R., Cavassini, M., et al. (2011). Association of pharmacogenetic markers with premature discontinuation of first-line anti-HIV therapy: an observational cohort study. J. Infect. Dis. 203, 246-257.

Lubomirov, R., di Iulio, J., Fayet, A., Colombo, S., Martinez, R., Marzolini, C., et al. (2010). ADME pharmacogenetics: investigation of the pharmacokinetics of the antiretroviral agent lopinavir coformulated with ritonavir. Pharmacogenet. Genomics 20, 217-230.

Mahungu, T., Smith, C., Turner, F., Egan, D., Youle, M., Johnson, M., et al. (2009). Cytochrome P450 2B6 $516 \mathrm{G}->\mathrm{T}$ is associated with plasma concentrations of nevirapine at both $200 \mathrm{mg}$ twice daily and $400 \mathrm{mg}$ once daily in an ethnically diverse population. HIV Med. 10, 310-317.

Maimbo, M., Kiyotani, K., Mushiroda, T., Masimirembwa, C., and Nakamura, Y. (2011). CYP2B6 genotype is a strong predictor of systemic exposure to efavirenz in HIV-infected Zimbabweans. Eur. J. Clin. Pharmacol. 68, 267-271.

Martis, S., Mei, H., Vijzelaar, R., Edelmann, L., Desnick, R. J., and Scott, S. A. (2012). Multi-ethnic cytochromeP450 copy number profiling: novel pharmacogenetic alleles and mechanism of copy number variation formation. Pharmacogenomics J. doi: 10.1038/tpj.2012.48 [Epub ahead of print].

Mehlotra, R. K., Bockarie, M. J., and Zimmerman, P. A. (2007). CYP2B6 $983 \mathrm{~T}>\mathrm{C}$ polymorphism is prevalent in West Africa but absent in Papua New Guinea: implications for HIV/AIDS treatment. Br. J. Clin. Pharmacol. 64, 391-395.

Melanson, S. E. F., Stevenson, K., Kim, H., Antin, J. H., Court, M. H., Ho, V. T., et al. (2010). Allelic variations in CYP2B6 and CYP2C19 and survival of patients receiving cyclophosphamide prior to myeloablative hematopoietic stem cell transplantation. Am. J. Hematol. 85, 967-971.

Meyer, R. P., Gehlhaus, M., Knoth, R., and Volk, B. (2007). Expression and 
function of cytochrome p450 in brain drug metabolism. Curr. Drug Metab. 8, 297-306

Miksys, S., Lerman, C., Shields, P. G., Mash, D. C., and Tyndale, R. F. (2003). Smoking, alcoholism and genetic polymorphisms alter CYP2B6 levels in human brain. Neuropharmacology 45, 122-132.

Mo, S.-L., Liu, Y.-H., Duan, W., Wei, M. Q., Kanwar, J. R., and Zhou, S.-F. (2009). Substrate specificity, regulation, and polymorphism of human cytochrome P450 2B6. Curr. Drug Metab. 10, 730-753.

Mukonzo, J. K., Röshammar, D., Waako, P., Andersson, M., Fukasawa, T., Milani, L., et al. (2009). A novel polymorphism in $\mathrm{ABCB} 1$ gene, $\mathrm{CYP} 2 \mathrm{~B} 6^{\star} 6$ and sex predict singledose efavirenz population pharmacokinetics in Ugandans. Br. J. Clin. Pharmacol. 68, 690-699.

Nakajima, M., Komagata, S., Fujiki, Y., Kanada, Y., Ebi, H., Itoh, K., et al. (2007). Genetic polymorphisms of CYP2B6 affect the pharmacokinetics/pharmacodynamics of cyclophosphamide in Japanese cancer patients. Pharmacogenet. Genomics 17, 431-445.

Nelson, D. R., Zeldin, D. C., Hoffman, S. M. G., Maltais, L. J., Wain, H. M., and Nebert, D. W. (2004). Comparison of cytochrome P450 (CYP) genes from the mouse and human genomes, including nomenclature recommendations for genes, pseudogenes and alternative-splice variants. Pharmacogenetics 14, 1-18.

Ngaimisi, E., Mugusi, S., Minzi, O. M., Sasi, P., Riedel, K.-D., Suda, A., et al. (2010). Long-term efavirenz autoinduction and its effect on plasma exposure in HIV patients. Clin. Pharmacol. Ther. 88, 676-684.

Nguyen, T.-A., Tychopoulos, M., Bichat, F., Zimmermann, C., Flinois, J.-P., Diry, M., et al. (2008). Improvement of cyclophosphamide activation by CYP2B6 mutants: from in silico to ex vivo. Mol. Pharmacol. 73, 1122 1133.

Niu, R.-J., Zheng, Q.-C., Zhang, J.-L., and Zhang, H.-X. (2011). Analysis of clinically relevant substrates of CYP2B6 enzyme by computational methods. J. Mol. Model. 17, 28392846.

Nyakutira, C., Röshammar, D., Chigutsa, E., Chonzi, P., Ashton, M., Nhachi, C., et al. (2008). High prevalence of the CYP2B6 516G$>\mathrm{T}\left({ }^{*} 6\right)$ variant and effect on the population pharmacokinetics of efavirenz in HIV/AIDS outpatients in Zimbabwe. Eur. J. Clin. Pharmacol. 64, 357-365.
Oda, Y., Hamaoka, N., Hiroi, T., Imaoka, S., Hase, I., Tanaka, K., et al. (2001). Involvement of human liver cytochrome P4502B6 in the metabolism of propofol. Br. J. Clin. Pharmacol. 51, 281-285.

Oscarson, M., Zanger, U. M., Rifki, O. F., Klein, K., Eichelbaum, M. and Meyer, U. A. (2006). Transcriptional profiling of genes induced in the livers of patients treated with carbamazepine. Clin. Pharmacol. Ther 80, 440-456.

Pelkonen, O., Turpeinen, M., Hakkola, J., Honkakoski, P., Hukkanen, J. and Raunio, H. (2008). Inhibition and induction of human cytochrome P450 enzymes: current status. Arch. Toxicol. 82, 667-715.

Peltoniemi, M. A., Saari, T. I., Hagelberg, N. M., Reponen, P., Turpeinen, M., Laine, K., etal. (2011). Exposure to oral S-ketamine is unaffected by itraconazole but greatly increased by ticlopidine. Clin. Pharmacol. Ther. 90, 296-302.

Penzak, S. R., Kabuye, G., Mugyenyi, P., Mbamanya, F., Natarajan, V., Alfaro, R. M., et al. (2007). Cytochrome P450 2B6 (CYP2B6) G516T influences nevirapine plasma concentrations in HIV-infected patients in Uganda. HIV Med. 8, 86-91.

Qin, W.-J., Zhang, W., Liu, Z.-Q., Chen, X.-P., Tan, Z.-R., Hu, D.-L., et al. (2012). Rapid clinical induction of bupropion hydroxylation by metamizole in healthy Chinese men. Br. J. Clin. Pharmacol. 74, 999-1004.

Raccor, B. S., Claessens, A. J., Dinh, J. C., Park, J. R., Hawkins, D. S., Thomas, S. S., et al. (2012). Potential contribution of cytochrome P450 2B6 to hepatic 4-hydroxycyclophosphamide formation in vitro and in vivo. Drug Metab. Dispos. 40, 54-63.

Radloff, R., Gras, A., Zanger, U. M., Masquelier, C., Arumugam, K. Karasi, J. C., et al. (2013). Novel CYP2B6 enzyme variants in a Rwandese population: functional characterization and assessment of in silico prediction tools. Hum. Mutat. doi: 10.1002/humu.22295 [Epub ahead of print].

Rae, J. M., Soukhova, N. V., Flockhart, D. A., and Desta, Z. (2002). Triethylenethiophosphoramide is a specific inhibitor of cytochrome P450 2B6: implications for cyclophosphamide metabolism. Drug Metab. Dispos. 30, 525-530.

Rakhmanina, N. Y., and van den Anker, J. N. (2010). Efavirenz in the therapy of HIV infection. Expert Opin. Drug Metab. Toxicol. 6, 95-103.

Ramírez, J., Innocenti, F., Schuetz, E. G., Flockhart, D. A., Relling, M. V.,
Santucci, R., et al. (2004). CYP2B6, CYP3A4, and CYP2C19 are responsible for the in vitro $\mathrm{N}$-demethylation of meperidine in human liver microsomes. Drug Metab. Dispos. 32, 930-936.

Remmer, H., Schoene, B., and Fleischmann, R. A. (1973). Induction of the unspecific microsomal hydroxylase in the human liver. Drug Metab. Dispos. 1, 224-230.

Restrepo, J. G., Martínez, C., GarcíaAgúndez, G., Gaviria, E., Laguna, J. J., García-Martín, E., etal. (2011). Cytochrome P450 CYP2B6 genotypes and haplotypesin a Colombian population: identification of novel variant CYP2B6 alleles. Pharmacogenet. Genomics 21, 773-778.

Ribaudo, H. J., Haas, D. W., Tierney, C., Kim, R. B., Wilkinson, G. R., Gulick, R. M., et al. (2006). Pharmacogenetics of plasma efavirenz exposure after treatment discontinuation: an Adult AIDS Clinical Trials Group Study. Clin. Infect. Dis. 42, 401-407.

Ribaudo, H. J., Liu, H., Schwab, M., Schaeffeler, E., Eichelbaum, M., Motsinger-Reif, A. A., et al. (2010). Effect of CYP2B6, ABCB1 and CYP3A5 polymorphisms on efavirenz pharmacokinetics and treatment response: an AIDS Clinical Trials Group study. J. Infect. Dis. 202, 717-722.

Richter, T., Mürdter, T. E., Heinkele, G., Pleiss, J., Tatzel, S., Schwab, M., et al. (2004). Potent mechanismbased inhibition of human CYP2B6 by clopidogrel and ticlopidine. $J$. Pharmacol. Exp. Ther. 308, 189-197.

Richter, T., Schwab, M., Eichelbaum, M. and Zanger, U. M. (2005). Inhibition of human CYP2B6 by $N, N^{\prime}, N^{\prime \prime}$. triethylenethiophosphoramide is irreversible and mechanismbased. Biochem. Pharmacol. 69, 517-524.

Rotger, M., Tegude, H., Colombo, S. Cavassini, M., Furrer, H., Décosterd, L., et al. (2007). Predictive value of known and novel alleles of CYP2B6 for efavirenz plasma concentrations in HIV-infected individuals. Clin. Pharmacol. Ther. 81, 557-566.

Roy, J.-N., Lajoie, J., Zijenah, L. S., Barama, A., Poirier, C., Ward, B. J., et al. (2005). CYP3A5 genetic polymorphisms in different ethnic populations. Drug Metab. Dispos. 33, 884-887.

Sadee, W., Wang, D., Papp, A. C., Pinsonneault, J. K., Smith, R. M. Moyer, R. A., et al. (2011). Pharmacogenomics of the RNA world: structural RNA polymorphisms in drug therapy. Clin. Pharmacol. Ther. 89, 355-365.
Saussele, T., Burk, O., Blievernicht, J. K., Klein, K., Nussler, A., Nussler, N., et al. (2007). Selective induction of human hepatic cytochromes P450 $2 \mathrm{~B} 6$ and 3A4 by metamizole. Clin. Pharmacol. Ther. 82, 265-274.

Shah, M. B., Pascual, J., Zhang, Q., Stout, C. D., and Halpert, J. R. (2011). Structures of cytochrome P450 2B6 bound to 4-benzylpyridine and 4(4-nitrobenzyl) pyridine: insight into inhibitor binding and rearrangement of active site side chains. Mol. Pharmacol. 80, 1047-1055.

Simonsson, U. S. H., Jansson, B., Hai, T. N., Huong, D. X., Tybring, G., and Ashton, M. (2003). Artemisinin autoinduction is caused by involvement of cytochrome P450 2B6 but not 2C9. Clin. Pharmacol. Ther. 74, 32-43.

Singh, G., Saxena, N., Aggarwal, A., and Misra, R. (2007). Cytochrome $\mathrm{P} 450$ polymorphism as a predictor of ovarian toxicity to pulse cyclophosphamide in systemic lupus erythematosus. J. Rheumatol. 34, 731-733.

Smith, G. B. J., Bend, J. R., Bedard, L. L., Reid, K. R., Petsikas, D., and Massey, T. E. (2003). Biotransformation of 4-(methylnitrosamino)1-(3-pyridyl)-1-butanone (NNK) in peripheral human lung microsomes. Drug Metab. Dispos. 31, 11341141.

Sridar, C., Kenaan, C., and Hollenberg, P. F. (2012). Inhibition of bupropion metabolism by selegiline: mechanism-based inactivation of human CYP2B6 and characterization of glutathione and peptide adducts. Drug Metab. Dispos. 40, 2256-2266.

Stewart, J. J., Berkel, H. J., Parish, R. C., Simar, M. R., Syed, A., Bocchini, J. A., et al. (2001). Single-dose pharmacokinetics of bupropion in adolescents: effects of smoking status and gender. J. Clin. Pharmacol. 41, 770-778.

Sueyoshi, T., Kawamoto, T., Zelko, I., Honkakoski, P., and Negishi, M. (1999). The repressed nuclear receptor CAR responds to phenobarbital in activating the human CYP2B6 gene. J. Biol. Chem. 274, 6043-6046.

Svensson, U. S., and Ashton, M. (1999). Identification of the human cytochrome P450 enzymes involved in the in vitro metabolism of artemisinin. Br. J. Clin. Pharmacol. 48, 528-535.

Takada, K., Arefayene, M., Desta, Z., Yarboro, C. H., Boumpas, D. T., Balow, J. E., et al. (2004). Cytochrome P450 pharmacogenetics as a predictor of toxicity and clinical response to pulse cyclophosphamide in lupus 
nephritis. Arthritis Rheum. 50, 2202 2210.

Talakad, J. C., Kumar, S., and Halpert, J. R. (2009). Decreased susceptibility of the cytochrome P450 2B6 variant K262R to inhibition by several clinically important drugs. Drug Metab. Dispos. 37, 644-650.

Telenti, A., and Zanger, U. M. (2008). Pharmacogenetics of anti-HIV drugs. Annu. Rev. Pharmacol. Toxicol. 48, 227-256.

Thelen, K., and Dressman, J. B. (2009). Cytochrome P450-mediated metabolism in the human gut wall. $J$. Pharm. Pharmacol. 61, 541-558.

Torimoto, Y., and Kohgo, Y. (2008). [Cyclophosphamide and CYP2B6]. Gan To Kagaku Ryoho 35, 1090-1093.

Totah, R. A., Sheffels, P., Roberts, T., Whittington, D., Thummel, K., and Kharasch, E. D. (2008). Role of CYP2B6 in stereoselective human methadone metabolism. Anesthesiology 108, 363-374.

Turpeinen, M., Raunio, H., and Pelkonen, O. (2006). The functional role of CYP2B6 in human drug metabolism: substrates and inhibitors in vitro, in vivo and in silico. Curr. Drug Metab. 7, 705-714.

Turpeinen, M., Tolonen, A., Uusitalo, J., Jalonen, J., Pelkonen, O., and Laine, K. (2005a). Effect of clopidogrel and ticlopidine on cytochrome P450 2B6 activity as measured by bupropion hydroxylation. Clin. Pharmacol. Ther. 77, 553-559.

Turpeinen, M., Uusitalo, J., Jouko, U., Jalonen, J., Jorma, J., Pelkonen, O., et al. (2005b). Multiple P450 substrates in a single run: rapid and comprehensive in vitro interaction assay. Eur. J. Pharm. Sci. 24, 123-132.

Turpeinen, M., and Zanger, U. M. (2012). Cytochrome P450 2B6: function, genetics, and clinical relevance. Drug Metabol. Drug Interact. 27, 185-197.

Walsky, R. L., and Obach, R. S. (2007). A comparison of 2-phenyl-2-(1piperidinyl)propane (ppp), 1, $1^{\prime}, 1^{\prime \prime}$ phosphinothioylidynetrisaziridine (thioTEPA), clopidogrel, and ticlopidine as selective inactivators of human cytochrome P450 2B6. Drug Metab. Dispos. 35, 2053-2059.

Wang, H., Faucette, S., Sueyoshi, T., Moore, R., Ferguson, S., Negishi, M., et al. (2003). A novel distal enhancer module regulated by pregnane $\mathrm{X}$ receptor/constitutive androstane receptor is essential for the maximal induction of CYP2B6 gene expression. J. Biol. Chem. 278, 14146-14152.

Wang, J., Sönnerborg, A., Rane, A., Josephson, F., Lundgren, S., Ståhle, L., et al. (2006). Identification of a novel specific CYP2B6 allele in Africans causing impaired metabolism of the HIV drug efavirenz. Pharmacogenet. Genomics 16, 191-198.

Wang, H., and Tompkins, L. M. (2008). CYP2B6: new insights into a historically overlooked cytochrome P450 isozyme. Curr. Drug Metab. 9, 598-610.

Ward, B. A., Gorski, J. C., Jones, D. R., Hall, S. D., Flockhart, D. A., and Desta, Z. (2003). The cytochrome P450 2B6 (CYP2B6) is the main catalyst of efavirenz primary and secondary metabolism: implication for HIV/AIDS therapy and utility of efavirenz as a substrate marker of CYP2B6 catalytic activity. J. Pharmacol. Exp. Ther. 306, 287-300.

Watanabe, T., Sakuyama, K., Sasaki, T., Ishii, Y., Ishikawa, M., Hirasawa N., etal. (2010). Functional characterization of 26 CYP2B6 allelic variants (CYP2B6.2-CYP2B6.28, except CYP2B6.22). Pharmacogenet. Genomics 20, 459-462.

Wilderman, P. R., and Halpert, J. R. (2012). Plasticity of CYP2B enzymes: structural and solution biophysical methods. Curr. Drug Metab. 13, 167-176.

Wyen, C., Hendra, H., Siccardi, M., Platten, M., Jaeger, H., Harrer, T., et al. (2011). Cytochrome P450 2B6 (CYP2B6) and constitutive androstane receptor (CAR) polymorphisms are associated with early discontinuation of efavirenz-containing regimens. J. Antimicrob. Chemother. 66, 2092-2098.

Xie, H., Griskevicius, L., Ståhle, L., Hassan, Z., Yasar, U., Rane, A., et al. (2006). Pharmacogenetics of cyclophosphamide in patients with hematological malignancies. Eur. J. Pharm. Sci. 27, 54-61.

Xie, H.-J., Yasar, U., Lundgren, S. Griskevicius, L., Terelius, Y., Hassan, M., etal. (2003). Role of polymorphic human CYP2B6 in cyclophosphamide bioactivation. Pharmacogenomics J. 3, 53-61.
Xu, C., Ogburn, E. T., Guo, Y., and Desta, Z. (2012). Effects of the CYP2B $6^{\star} 6$ allele on catalytic properties and inhibition of CYP2B6 in vitro: implication for the mechanism of reduced efavirenz metabolism and other CYP2B6 substrates in vivo. Drug Metab. Dispos. 40, 717-725.

Yamanaka, H., Nakajima, M., Fukami, T., Sakai, H., Nakamura, A., Katoh, M., etal. (2005). CYP2A6 AND CYP2B6 are involved in nornicotine formation from nicotine in humans: interindividual differences in these contributions. Drug Metab. Dispos. 33, 1811-1818.

Yamazaki, H., Inoue, K., Hashimoto, M., and Shimada, T. (1999). Roles of CYP2A6 and CYP2B6 in nicotine C-oxidation by human liver microsomes. Arch. Toxicol. 73, 65-70.

Yang, X., Zhang, B., Molony, C., Chudin, E., Hao, K., Zhu, J., et al. (2010). Systematic genetic and genomic analysis of cytochrome P450 enzyme activities in human liver. Genome Res. 20, 1020-1036.

Yao, S., Barlow, W. E., Albain, K. S., Choi, J.-Y., Zhao, H., Livingston, R. B. et al. (2010). Gene polymorphisms in cyclophosphamide metabolism pathway, treatment-related toxicity, and disease-free survival in SWOG 8897 clinical trial for breast cancer. Clin. Cancer Res. 16, 6169-6176.

Yimer, G., Amogne, W., Habtewold, A., Makonnen, E., Ueda, N., Suda, A. et al. (2011). High plasma efavirenz level and $\mathrm{CYP} 2 \mathrm{~B} 6^{\star} 6$ are associated with efavirenz-based HAARTinduced liver injury in the treatment of naïve HIV patients from Ethiopia: a prospective cohort study. Pharmacogenomics J. 12, 499-506.

Yuan, J., Guo, S., Hall, D., Cammett, A. M., Jayadev, S., Distel, M., et al. (2011). Toxicogenomics of nevirapine-associated cutaneous and hepatic adverse events among populations of African, Asian, and European descent. AIDS 25, 12711280.

Zanger, U. M., and Hofmann, M. H. (2008). Polymorphic cytochromes P450 CYP2B6 and CYP2D6: recent advances on single nucleotide polymorphisms affecting splicing. Acta Chim. Slov. 55, 38

Zanger, U. M., Klein, K., Saussele, T., Blievernicht, J., Hofmann, M. H. and Schwab, M. (2007). Polymorphic
CYP2B6: molecular mechanisms and emerging clinical significance. Pharmacogenomics 8, 743-759.

Zhang, H., Amunugama, H., Ney, S., Cooper, N., and Hollenberg, P. F. (2011a). Mechanism-based inactivation of human cytochrome P450 2B6 by clopidogrel: involvement of both covalent modification of cysteinyl residue 475 and loss of heme. Mol. Pharmacol. 80, 839-847.

Zhang, H., Sridar, C., Kenaan, C., Amunugama, H., Ballou, D. P., and Hollenberg, P. F. (2011b). Polymorphic variants of cytochrome P450 2B6 (CYP2B6.4-CYP2B6.9) exhibit altered rates of metabolism for bupropion and efavirenz: a chargereversal mutation in the $\mathrm{K} 139 \mathrm{E}$ variant (CYP2B6.8) impairs formation of a functional cytochrome p450reductase complex. J. Pharmacol. Exp. Ther. 338, 803-809.

Zukunft, J., Lang, T., Richter, T., HirschErnst, K. I., Nussler, A. K., Klein, K., et al. (2005). A natural CYP2B6 TATA box polymorphism $(-82 \mathrm{~T}->\mathrm{C})$ leading to enhanced transcription and relocation of the transcriptional start site. Mol. Pharmacol. 67, 17721782.

Conflict of Interest Statement: Ulrich M. Zanger is a named coinventor of a patent on the detection of specific CYP2B6 polymorphisms for diagnostic purposes. Kathrin Klein declares no conflict of interest.

Received: 19 October 2012; accepted: 14 February 2013; published online: 05 March 2013.

Citation: Zanger UM and Klein K (2013) Pharmacogenetics of cytochrome P450 $2 B 6$ (CYP2B6): advances on polymorphisms, mechanisms, and clinical relevance. Front. Genet. 4:24. doi: 10.3389/ fgene.2013.00024

This article was submitted to Frontiers in Pharmacogenetics and Pharmacogenomics, a specialty of Frontiers in Genetics.

Copyright (C) 2013 Zanger and Klein. This is an open-access article distributed under the terms of the Creative Commons Attribution License, which permits use, distribution and reproduction in other forums, provided the original authors and source are credited and subject to any copyright notices concerning any thirdparty graphics etc. 